\title{
Mujeres y jefatura del hogar en el mundo rural leonés durante la Edad Moderna
}

\author{
María José PÉREz Álvarez \\ Universidad de León \\ maria-jose.perez@unileon.es
}

Recibido: 20 de octubre de 2010

Aceptado: 22 de junio de 2012

\section{RESUMEN}

Si bien a lo largo de las últimas décadas han proliferado los estudios sobre mujeres, para la provincia de León el tema ha estado un tanto descuidado por la historiografía modernista. Este trabajo, con el que pretendemos contribuir a cubrir una parte de esa parcela de la Historia Social, lo hemos centrado en el análisis de la jefatura del hogar. Para su estudio hemos utilizado los Libros de Familia del Catastro del marqués de la Ensenada y una serie de padrones de cronología muy variada. A su vez, y dada la diversidad paisajística y, por ende, económica del territorio leonés, hemos cuantificado el número de mujeres que detentaban la jefatura del hogar por comarcas, para conocer la influencia del medio sobre esa variable, también analizamos la evolución de esos resultados y las formas de corresidencia de esas mujeres.

Palabras clave: Edad Moderna, León, mujeres, jefatura del hogar.

\section{Women and Head of Household in Early Modern Rural León, Spain}

\begin{abstract}
Although women's studies have proliferated in recent decades, this subject has been rather neglected by Early Modern Historiography as regards the province of León, in the northwest of Spain. The aim of this study is to make a contribution to this aspect of Social History, focusing on an analysis of household heads. To this end, we analysed the Family Registers (Libros de Familia) of the mid-eighteenth-century famous census known as Catastro of Ensenada, and a series of registers from a wide range of dates. Given the diversity of territories, and consequently, of economic activities in the province of León, we quantified the number of women acting as head of household by region, in order to determine the influence of the environment on this variable. Finally, we also study how this data changed over time, and the forms of co-residence among these women.
\end{abstract}

Key words: Early Modern Era, León, Women, Household head. 
En 1787 la provincia de León ${ }^{1}$ tenía 235.828 habitantes $^{2}$, de los cuales 119.441 eran mujeres (50,6\%). De éstas, solamente el 3,7\% residían en el mundo urbano, es decir, en León o Astorga; el 6\% en villas y núcleos semiurbanos ${ }^{3}$ y el 90,2\% restante lo hacían en el ámbito rural. Será en este grupo mayoritario en el que vamos a centrar nuestro estudio y, dentro del amplio abanico de posibilidades que ofrece su investigación, hemos escogido para esta primera aproximación la jefatura del hogar. Pues unas cuantas de esas mujeres, que se distribuían por las numerosas y pequeñas comunidades de aldea de la provincia, ejercían como cabezas de familia, lo que les otorgaba la responsabilidad de cuanto acontecía en su hogar; por el contrario, la gran mayoría, quedaban invisibilizadas tras la figura del padre o del esposo.

El estudio lo vamos a realizar tomando como referencia el territorio, para lo cual, nos centraremos, fundamentalmente, en el número de hogares que estaban bajo la dirección de mujeres en las distintas comarcas leonesas, la edad que tenía cada una de ellas, su estado civil o los avances y retrocesos que podían sufrir esos hogares en función de las coyunturas económicas o demográficas. El motivo de comenzar con un enfoque diferencial de este tipo se debe a la necesidad de conocer si verdaderamente existieron, en este sentido, diferentes modelos de organización en una provincia donde las estructuras económicas fueron tan diversas. En caso de que así fuera será necesario delimitarlos y definirlos, buscar las causas que los desencadenaron o las pautas de adaptación.

\section{LA JEFATURA FEMENINA EN LA PROVINCIA DE LEÓN}

El jefe del hogar, entendido éste como conjunto de personas -entre las cuales podían existir o no lazos de parentesco- que compartían una misma vivienda y que formaban un bloque de cara al exterior, era el responsable del comportamiento -tanto de puertas hacia dentro como del que proyectaba fuera de él ${ }^{4}$ - de todos los miembros de esa unidad básica de convivencia, y también económica. Pero teniendo en cuenta que durante la Edad Moderna casi la totalidad de los hogares leoneses, más si cabe en el mundo rural, estuvieron formados por individuos entre los cuales existían vínculos de consanguinidad, siendo el núcleo conyugal la principal pieza aglutinadora, podemos equiparar los términos hogar y familia. El tipo de familia más extendido era el for-

\footnotetext{
1 Este trabajo forma parte de un proyecto de investigación titulado Marginación y respuesta social en el Noroeste de la Península Ibérica durante el Antiguo Régimen, financiado por el Ministerio de Ciencia e Innovación (Ref. HAR2010-17780).

2 No están incluidos los religiosos y religiosas regulares que vivían en los diferentes conventos y monasterios de la provincia.

3 Hemos considerado núcleos semiurbanos aquellos que, no alcanzando la categoría de ciudad, se distinguían del resto por el volumen de población que aglutinaban y los servicios que ofrecían. Es el caso de Ponferrada, Valderas, Sahagún o Grajal de Campos, donde habitaban 1.502 personas, 2.545, 3.137 y 1.095, respectivamente.

4 Sobre los conceptos de hogar y familia vid. ReHER, D. S.: Familia, población y sociedad en la provincia de Cuenca. 1700-1900, Madrid, Siglo XXI, 1988, pp. 149-150.
} 
mado por padres e hijos, por lo que recaía en el varón ${ }^{5}$, bajo la cobertura jurídica de la patria potestad, la responsabilidad del hogar, su dirección y el control sobre todos sus miembros. Para ejercer ese compromiso social, el padre estaba amparado por la legislación civil y eclesiástica y auxiliado por la propaganda de los moralistas. A su persona estaban supeditados todos los individuos que cohabitaban con él: esposa, hijos y otros parientes ${ }^{6}$. No obstante, y aún siendo esa realidad la predominante, las elevadas tasas en las que se movió la mortandad y celibato femenino durante el Antiguo Régimen, sobre todo en algunas zonas de la provincia, elevaron, con relativa frecuencia, a las mujeres al ejercicio de la jefatura de la unidad doméstica ${ }^{7}$.

Durante este periodo histórico, y de acuerdo con la concepción imperante de sociedad patriarcal, sólo las mujeres célibes y las viudas, es decir aquellas que no estaban sometidas a la patria potestad paterna o marital, detentaban la jefatura del hogar ${ }^{8}$. Esas mujeres, además, poseían personalidad jurídica, al contrario de lo que sucedía cuando vivían sus maridos o padres, ya que entonces eran ellos quienes ejercían como sus representantes legales ${ }^{9}$. No obstante, aunque con un peso porcentual muy bajo, también pueden aparecen al frente de la familia mujeres casadas, pero en este caso únicamente la ausencia prolongada del marido les permitía asumir temporalmente esa función.

A nivel provincial, la información más completa para poder cuantificar la presencia de mujeres al frente del hogar es la que se puede extraer de los libros de familia del Catastro del marqués de la Ensenada, a pesar de que los datos no siguen un es-

5 Como señaló Domínguez Ortiz, la familia conservaba "incólume" el carácter patriarcal. DomíngUEz Ortiz, A.: Sociedad y Estado en el siglo XVI/l, Madrid, 1986, p. 321. Vid. Gacto, E.: «Entre la debilidad y la simpleza: La mujer ante la ley», Historia 16, 145 (1988), pp. 24-32, p. 26

6 Durante la Edad Moderna, la subordinación de las mujeres se fundamentaba en la obediencia al esposo. Vid. Davis, N.: "Un mundo al revés: las mujeres en el poder", en AmElang, J. S. y Nash, M. J. (coords.): Historia y Género: las mujeres en la Europa Moderna y Contemporánea, Valencia, Universidad de Valencia, 1990, pp. 59-92; Stone, L.: Familia, sexo y matrimonio en Inglaterra (1500-1800), México, Fondo de Cultura Económica, 1990, p. 115. Sobre la posición que las mujeres ocupaba en el matrimonio Vid. HERNÁNDEZ Bermejo, M. A.: La familia extremeña en los tiempos modernos, Badajoz, Diputación de Badajoz, 1990, pp. 64 y ss.

7 Tal y como ha señalado López-Cordón, la situación que poseían las mujeres en la familia era su "identidad social", la que "definía sus funciones en el seno de la comunidad y, a su "presuponía determinadas exigencias morales". LóPEz-Cordón Cortezo, M. ${ }^{a}$ V.: "mujer y familia en la Edad Moderna, ¿dos perspectivas complementarias?”, en Chacón Jiménez, F. y Hernández Franco, J. (eds.): Espacios sociales, universos familiares. La familia en la historiografía española, Murcia, Universidad de Murcia, 2007, pp.193-219, p.202

8 García GonzÁlez, F.: "El grupo doméstico en la Castilla rural. Algunos indicadores a mediados del siglo XVIII en la zona centro-meridional”, en ArAndA PÉREz, F. J. (coord.): El mundo rural en la Edad Moderna. Actas de la VII Reunión Cientifica de la Fundación Española de Historia Moderna, Cuenca, Universidad de Castilla-La Mancha, 2004, pp. 153-175. pp. 162-163. En ambos casos era el fallecimiento del hombre lo que coloca a las mujeres al frente del hogar. Respecto al regreso de las viudas al hogar paterno, Vid. SESMERO CutAnda, E.: "La mujer y la casa reflexiones metodológicas sobre el aporte económico femenino al hogar rural popular de Vizcaya (finales del siglo XVI-ca. 1879)", en Imízcoz, J. M.: Casa, familia y sociedad, Bilbao, Universidad del País Vasco, 2004, pp. 331-367 y 340.

9 El recuperar los bienes dotales, tras la viudedad, suponía un paso hacia la libertad, eso sí, siempre y cuando su cuantía les garantizara la futura estabilidad económica. Esa circunstancia influyó en las bajas tasas de segundas nupcias de las mujeres de las élites. Brodsky, V.: "Viudas en Londres a finales del reinado de Isabel I: nuevas nupcias, oportunidades económicas y orientaciones familiares», en VV.AA.: El mundo que hemos ganado. Estudios sobre población y estructura social. Homenaje a Peter Laslett en su 70 aniversario, Madrid, Ministerio de Trabajo y Seguridad Social, 1990, pp. 157-196. 
quema uniforme en todas las localidades. En algunas, los responsables de elaborarlos tan sólo recogieron los más básicos de la unidad familiar, caso del nombre del cabeza de familia o la relación de parentesco, o de otro tipo, que existía entre los corresidentes. En otras, además, nos facilitaron la edad de todas o parte de esas personas y la actividad económica que desarrollaban. A nivel general, se puede decir que las noticias que nos proporcionaron de los agregados domésticos son muy someras, $\mathrm{y}$, en cualquier caso, son más completas en los hogares encabezados por varones que en los de jefatura femenina. A su vez, esta documentación sólo nos permite visualizar un momento del ciclo vital de una institución cuya naturaleza era muy dinámica, debido a las elevadas tasas de mortandad ordinaria a la que estaba sometida la sociedad. No obstante, y a pesar de tratarse de una visión estática, esa información será la que nos ofrece el catastro de gran utilidad para revelarnos las pautas de organización familiar imperante.

También de gran interés nos resultaron algunos de los padrones que se confeccionaron, con finalidad fiscal, a lo largo de la Edad Moderna. Ahora bien, son muy pocos los que nos ofrecen algún dato que vaya más allá del nombre de la persona que ostentaba la representación del hogar. Otro inconveniente de esta documentación es la gran dispersión geográfica y cronológica que presenta. No obstante, y a pesar de todo lo expuesto, nos resultan muy útiles para ayudarnos a completar la visión que se desprende del catastro, sobre el papel que las mujeres leonesas desempeñaban al frente del hogar.

Estar a la cabeza de un núcleo familiar significaba desempeñar el papel más importante que podía recaer en uno de sus miembros. Cuando las mujeres alcanzaban ese puesto ejercían todas las funciones que anteriormente había desempeñado el esposo o el padre ${ }^{10}$. Pasaban a ser las responsables de la estructura socioeconómica del hogar, se encargaban de buscar los medios para satisfacer las necesidades del mismo o de tomar las decisiones que afectaban a su proyección en el exterior. Esa categoría que adquirían debe entenderse en un contexto en el que la patria potestad y la subordinación femenina al marido, al padre o al hermano, era impulsada desde todas las esferas del poder. Pero la importancia de esas mujeres no equivalía a una transformación de igual calado en su posición dentro de la sociedad, ya que esa no sufría grandes cambios. Su papel, a pesar de la responsabilidad que asumían en la toma de decisiones, continuaba estando cercenado por la legislación. Por ejemplo, hasta finales del siglo XIX a una mujer no se le asignaba automáticamente la "curaduría" de los hijos menores, lo que en el ámbito del derecho público significaba que estaba desposeída de la

10 Las cinco funciones básicas de un hogar pasaban a estar ejercidas por las mujeres, que hasta entonces habían visto como su parcela de poder se constreñía a cuestiones domésticas. En palabras de Ángel Rodríguez Sánchez: "la función económica, la toma de decisiones, y el control de todo el patrimonio, corresponden al padre; la función doméstica, el trabajo y atención de la casa, corresponden a la madre; y la estrategia familiar, lo que define el comportamiento externo, económico y social de los miembros de la familia, también corresponde al padre. En síntesis, puede significarse que en el ámbito de lo privado la madre tiene una cierta autoridad; pero la proyección social de la familia siempre es derecho de la patria potestad”. Rodríguez SÁnchez, A.: "El poder familiar: la patria potestad en el Antiguo Régimen", Chrónica Nova 18 (1990), pp. 365-380 
representación legal de los mismos ${ }^{11}$. A su vez, y en caso de haber sido la depositaria de dicha responsabilidad, esa peligraba si decidía volver a casarse.

\begin{tabular}{|l|c|c|c|c|c|}
\hline & \multicolumn{5}{|c|}{ Cuadro n $^{\mathbf{0}} \mathbf{1 .}$ La jefatura del hogar (1752) } \\
\hline & \multicolumn{2}{|c|}{ Hombres } & \multicolumn{2}{c|}{ Mujeres } & Total \\
\hline & $\mathrm{N}^{\mathbf{0}}$ & $\%$ & $\mathrm{~N}^{\mathbf{0}}$ & $\%$ & $\mathrm{~N}^{\mathbf{0}}$ \\
\hline Bierzo & 227 & 79,9 & 57 & 20,1 & 284 \\
\hline Montaña & 905 & 80,9 & 213 & 19,1 & 1118 \\
\hline Cepeda & 119 & 81,0 & 28 & 19,0 & 147 \\
\hline Páramo & 197 & 84,5 & 36 & 15,5 & 233 \\
\hline Órbigo & 169 & 87,1 & 25 & 12,9 & 194 \\
\hline Cea-Campos & 372 & 88,6 & 48 & 11,4 & 420 \\
\hline TOTAL & 1989 & 83,0 & 407 & 17,0 & 2396 \\
\hline \multicolumn{6}{|c|}{} \\
\hline
\end{tabular}

Por otro lado, esas mujeres tampoco desempeñaron la jefatura del hogar en las mismas condiciones económicas que los varones. A nivel provincial, solamente el $3,7 \%$ de las unidades familiares regidas por un hombre carecían de tierra y la media por unidad de producción era de 5 hectáreas, mientras que entre las féminas, esas cifras eran 7,4\% y 3, respectivamente. Para seguir ahondando en esas diferencias, señalar que algo más del $56,8 \%$ de las explotaciones masculinas poseían suficiente patrimonio raíz para ser consideradas autosuficientes y de las detentadas por mujeres esa circunstancia sólo la encontramos en una de cada cuatro. Esas desigualdades de carácter económico, que se constatan en los recursos disponibles por hombres y mujeres que rigen los destinos de una familia, aún se acentuaban más en algunas comarcas, caso, por ejemplo, de la montaña, donde solamente el 12,1\% de las jefas de hogar poseían tierra suficiente para mantenerse. La pobreza en la que desenvolvía la vida de esas mujeres las condujo a buscar medios de vida alternativos que les permitieran subsistir, pero en numerosas ocasiones las actividades complementarias que desarrollaron serían difíciles de rentabilizar, debido a la autarquía entre la que se movían, y no las apartaron de la marginalidad económica ${ }^{12}$. Entre los trabajos complementarios a los que recurrieron las mujeres leonesas, para sacar adelante la unidad familiar, cabe destacar la actividad textil, aunque en algunas comarcas la disponibilidad de otros recursos y la demanda del mercado les permitió desarrollar otro tipo de actividades, como, por ejemplo, la alfarería en algunas localidades del Bierzo o en tierras del Jamuz.

A mediados del siglo XVIII, y a tenor de los datos aportados por el catastro de Ensenada, el 17\% de los núcleos familiares del ámbito rural leonés tenían al frente a

11 A este respecto Vid. Gacto, E.: "El grupo familiar de la Edad Moderna en los territorios del Mediterráneo hispánico: una visión jurídica”, en CHAcón, F. (ed.): La familia en la España Mediterránea (siglos XV-XIX), Barcelona, Crítica, 1987, pp. 36-64, y GACTO, op. cit. (n. 5), pp. 29 y ss.

12 La ausencia de esposo y de una familia eran dos de las circunstancias familiares que arrojaban a una mujer a la pobreza. Ehmer, J.: "El matrimonio", en Kertzer D. y BArbagli, M.: Vida familiar desde la revolución francesa hasta la primera guerra mundial: 1789-1913, Barcelona, Paidós, 2004, pp. 411-462. 
una mujer ${ }^{13}$ (cuadro ${ }^{\circ} 1$ ). En esos hogares, de jefatura femenina, la edad media de sus responsables era, por término medio, 7 años superior a la de los masculinos. De todas formas esa media esconde diferencias apreciables, pues se dieron casos en que esa distancia fue superior, alcanzando casi los 10 años -como fue en Cea-Campos o en las Vegas, donde los varones tenían 39,7 y 41,6 años y las mujeres 49 y 49,7 respectivamente- $\mathrm{y}$ otros donde apenas tuvo relevancia, como en la montaña, donde los hombres tenía 44,7 años y las mujeres $46,8{ }^{14}$. No obstante, esa medida central estuvo sometida a constantes oscilaciones, dependiendo de las circunstancias coyunturales del momento, por lo que no sería factible extrapolar las cifras a toda la Edad Moderna.

En los territorios de montaña o semimontaña ${ }^{15}$, caso éste último de las comarcas de la Cepeda o el Bierzo Alto, es donde nos encontramos con las cifras más elevadas de mujeres al frente de la unidad de corresidencia, con porcentajes que oscilaban entre el 19,1 y $20 \%$. Incluso esa media fue ampliamente rebasada en algunas localidades, como, por ejemplo, en las bercianas de Santibáñez y San Esteban o en Riaño. En las primeras la cota de representación femenina, por aquellas mismas fechas, llegó a alcanzar el $24,7 \%$ y en la otra un $25,8 \%$. En el extremo opuesto estaban las comarcas de la mitad sur de la provincia, donde los porcentajes de jefatura femenina se movían entre el $11,4 \%$ y el $15,5 \%{ }^{16}$. Por otro lado, y para poder valorar en su justa medida los resultados que nos ofrece la montaña, hemos de tener en cuenta que en ese ámbito una de las estrategias familiares a las que se recurría, para controlar de alguna forma la reproducción social, era la de mejorar a algún descendiente. Como consecuencia de esa práctica, los porcentajes de mujeres viudas que accedían a la jefatura del hogar inevitablemente se resentirían. La condición para premiar a un hijo era que tras el matrimonio debía de residir en la casa paterna, por lo tanto, todas aquellas mujeres que perdieran a un esposo que hubiera sido privilegiado en la herencia, sobre todo las

13 Hemos tomado una muestra de seis comarcas de la provincia, en la que buscamos que estuvieran reflejados todos los modelos agrícolas: el extensivo cerealístico -Cea-Campos-, extensivo combinado con viñedo -Páramo-, las vegas fértiles -Órbigo- el modelo de montaña, y aquellos otros que podemos considerar de transición -Bierzo Alto y Cepeda.

14 Se trata de edades elevadas si las comparamos con las extremeñas de Coria, donde la media era de 37 años. Blanco Carrasco, J. P.: Demografía, familia y sociedad en la Extremadura Moderna, 1500-1860, Cáceres, Universidad de Extremadura, 1999, p.300.

15 La elevada representación de mujeres al frente del hogar en los territorios de montaña estaba relacionada con las dificultades para contraer matrimonio, debido a la desproporción que existía entre sexos a causa de la emigración masculina. Un caso similar al constatado por Bideau, pero en el que el desequilibrio estaba motivado por otras circunstancias. BIDEAU, A.: "A demographic and social analysis of widowhood and remarriage: the example of the castellany of Thoissey-en-Dombes, 1670-1840", Journal of family History, 5 (1980), pp. 28-43.

16 Este resultado es muy similar al de Alcaraz, donde el porcentaje de mujeres que ostentaban la representación de la unidad residencial era del $15 \%$. Por su parte, los de la montaña o semimontaña se asemejan más a los del ámbito rural asturiano, donde se movían entre el 15 y $20 \%$, al global gallego, que era de 19,2\% o al de la familia cacereña, 16,6\%. GARcía GonZÁlez, F.: La sierra de Alcaraz en el siglo XVIII. Población, familias y estructura agraria, Albacete, Diputación de Albacete, 1998, p. 213; LóPEz IGLESIAS, F.: El grupo doméstico en la Asturias del siglo XVII, Oviedo, Real Instituto de Estudios Asturianos, 1999, p. 89. Rey Castelao, O. y Rial García, S.: "Las viudas en Galicia a finales del Antiguo Régimen”, Chrónica Nova, 34 (2008), pp. 91-122 y p. 94. Hernández Bermejo M. A. y Testón NúÑEz, I.: "La familia cacereña a finales del Antiguo Régimen”, Studia Histórica. Historia Moderna, 9 (1991), pp. 143-158, p. 147. 
jóvenes, quedarían enraizadas en la familia política, no alcanzando la jefatura hasta que falleciera el suegro, o incluso la suegra.

Una serie de padrones, elaborados a lo largo de la Edad Moderna en distintas comarcas leonesas, nos ofrecen la posibilidad de acercarnos a la evolución coyuntural de la responsabilidad femenina al frente del hogar. Lo primero que observamos son las constantes oscilaciones a las que estuvieron sometidos los porcentajes que nos reflejan esa presencia femenina. Así, por ejemplo, se puede comprobar como en el concejo de Laciana, en los quince años transcurridos entre 1761 y 1775 , se pasó de un $21,6 \%$ de hogares tutelados por mujeres a un $17,5 \%$ (cuadro $n^{\circ} 2$ ). Ese retroceso coincidió con un incremento de tipologías familiares complejas, en las cuales el papel de la mujer viuda quedaba diluido a la sombra del suegro o, en su caso, y menos frecuentemente, del padre. Otro tanto les ocurría a las solteras, las cuales pasaban a ser absorbidas en los hogares del hermano mejorado. No obstante, en ese mismo concejo, tanto en el último tercio del siglo XVIII como a comienzos de la misma centuria, el porcentaje de mujeres que tuvo que responsabilizarse del hogar, aunque sólo fuera transitoriamente, fue mayor que el reflejado por los padrones. Se debe esa circunstancia a que, en el momento de realizarse el recuento, algunas de las unidades familiares que aparecen conducidas por un varón esconden la ausencia temporal del mismo. Concretamente, en 1718 había 15 hogares en los que el cabeza de familia se hallaba fuera de Laciana cuando se elaboró el vecindario. Esta circunstancia fue muy frecuente en los territorios de montaña, debido a que las necesidades económicas llevaban con frecuencia a los varones a ejercer trabajos temporales. Es el caso de los arrieros, pastores o temporeros agrícolas.

Por lo que respecta a la representación que, dentro del colectivo femenino adulto, tenían las mujeres que ejercían como jefas del hogar, se puede decir que era baja a mediados del siglo XVIII. Para realizar este cálculo hemos prescindido de las que aún se hallaban subordinadas a la autoridad paterna,y de las que se encontraban bajo el techo de algún otro pariente. Es decir, sólo hemos tenido en cuenta a las que ostentaban algún compromiso al frente de una unidad doméstica. El resultado es el siguiente: las mujeres adultas que tenían a su cargo un hogar representaban entre el 17,8\%, en Tierras de Campos o el Órbigo, y casi el 30\% en algunos concejos montañeses. El resto eran mujeres que, por su condición de casadas, estaban subordinadas al marido. Entre las féminas que habían accedido a la jefatura del hogar, el estado civil más extendido era el de la viudedad, aunque en algunas las zonas la soltería alcanzaba cierto grado de representación, sin desbancar nunca al otro. Las cifras de célibes respecto al total de mujeres adultas se movieron en un amplio abanico, que osciló entre el $1 \%$ y el $10 \%$, repitiéndose, tanto en máximos como en mínimos, los territorios anteriormente señalados.

En conjunto, podemos decir que a mediados del siglo XVIII en aquellas zonas donde las condiciones orográficas eran más difíciles y la emigración masculina tenía cierto peso cuantitativo, uno de cada cinco hogares, al menos, estaba gobernado por una mujer. Por el contrario, en los territorios que aparentemente gozaban de mejores condiciones para el desarrollo de la agricultura, las féminas controlaban entre una sexta y una novena parte de los mismos. En consecuencia, todo parece indicar que, 
en la provincia de León, a mayor pobreza del medio mayor facilidad para que las mujeres alcanzaran un papel destacado en la unidad doméstica.

\subsection{COYUNTURA ECONÓMICA Y CAMBIOS EN LA DIRECCIÓN DEL HOGAR}

Cruzando los datos que poseemos para mediados del siglo XVIII con los que nos ofrecen los Expedientes de Hacienda de 1561, podemos comparar las cifras de mujeres que ostentaban la jefatura de las unidades domésticas en la provincia de León en dos momentos puntuales y, de este modo, conocer el grado de estabilidad de esa variable (cuadro $\mathrm{n}^{\circ}$ 2). A mediados del siglo XVI, dependiendo de territorio, el porcentaje de mujeres al frente del hogar fluctuaba entre el 8 y $14,4 \%{ }^{17}$. Esas cifras, en conjunto, fueron superadas en casi un cuarenta por ciento dos siglos después. Por otro lado, y contrariamente a lo que ocurriría a mediados del siglo XVIII, la representación femenina era más baja en la montaña oriental leonesa que en otras zonas. Posiblemente, la explicación a esas oscilaciones, más o menos bruscas, hemos de buscarla en las coyunturas demográficas y económicas que marcaban el periodo en que se realizó el recuento. A mediados del siglo XVI el crecimiento agrario experimentado, en gran medida gracias a la puesta en cultivo de nuevas tierras ${ }^{18}$, se plasmó en un aumento de población, que, a su vez, sería el resultado de una mayor intensidad matrimonial, la cual enraizaba a las mujeres célibes o viudas en nuevos núcleos familiares. Por su parte, a mediados del siglo XVIII, se estaba ante una tesitura bien diferente. Los efectivos demográficos estaban en sus cotas más elevadas y la producción había tocado techo ${ }^{19}$. Ante esas circunstancias, sobre todo en aquellos lugares en los que no se habían desarrollado nuevos métodos productivos, se tenían que poner en marcha mecanismos que controlaran los sistemas de reproducción social, por lo tanto el matrimonio, que era la variable demográfica que más afectaba a la jefatura femenina.

17 Los resultados cosechados en Tierras de León y los Oteros se aproximan a los obtenidos, en la misma fecha, para el ámbito rural vallisoletano y la Bureba. Vid. Bennassar, B.: Valladolid en el Siglo de Oro. Una ciudad castellana y su entorno agrario en el Siglo XVI, Valladolid, Ámbito, 1989, pp. 180-181; BRUMONT, F.: Campo y campesinos en Castilla la Vieja en tiempos de Felipe II, Madrid, Siglo XXI, 1984, p. 79. A su vez, son ligeramente más elevados que los de la castilla rural de los dos primeros tercios del mismo Siglo - 12,7 y 13,2, respectivamente-. Vid. MoliniÉ-Bertrand, A.: Au Siècle D'Or L'Espagne et ses hommes. La population du Royaume de Castille au XVIe siècle, Paris, Economica, 1985, pp. 341-345.

18 En 1584 las comunidades de aldea babianas declaraban tener «... Provisión de su Majestad por tiempo de 60 años, para labrar cierta cantidad de tierra concejil para sembrarla de pan, atento a las pocas tierras que tienen y a la esterilidad del término y tierras». Esa tierra se repartía por igual «entre el total de vecinos, ricos o pobres», AGS [Archivo General de Simancas], EH [Expedientes de Hacienda], Leg. 56.

19 Vid. Pérez García, J. M.: "Demografía leonesa en el Antiguo Régimen” y Rubio Pérez, L. M.: “Tierra y agricultura, estructuras, distribución y usos del espacio productivo”, en RuBio Pérez, L. M. (coord.): Historia de León, Vol. III, León, Universidad de León, 1999, pp. 188-201 y 318-344. 


\begin{tabular}{|c|c|c|c|c|}
\hline \multicolumn{5}{|c|}{ Cuadro ${ }^{0} 2$. La jefatura femenina en la provincia de León en la Edad Moderna. } \\
\hline \multirow[b]{2}{*}{ Territorio } & \multirow[b]{2}{*}{ Año } & \multirow[b]{2}{*}{$\mathbf{N}^{0}$ familias } & \multicolumn{2}{|c|}{ Jefatura femenina } \\
\hline & & & $\mathrm{N}^{\mathrm{a}}$ de hogares & $\%$ \\
\hline Montaña Oriental & 1561 & 326 & 26 & 8 \\
\hline Montaña Oriental & S. XVII & 220 & 22 & 10 \\
\hline Montaña Oriental & 1752 & 232 & 50 & 21,6 \\
\hline Liegos & 1580 & 54 & 7 & 12,9 \\
\hline Tierras de León & 1561 & 161 & 23 & 14,3 \\
\hline Tierras de León & 1680 & 420 & 60 & 14,4 \\
\hline Los Oteros & 1561 & 585 & 84 & 14,4 \\
\hline Cea-Campos & 1561 & 218 & 24 & 11 \\
\hline Concejo de Sena de Luna & 1628 & 56 & 8 & 14,3 \\
\hline Concejo de Sena de Luna & 1782 & 133 & 18 & 13,5 \\
\hline Concejo de Sena de Luna & 1806 & 133 & 22 & 16,5 \\
\hline Concejo de Babia de Abajo & 1761 & 424 & 96 & 22,6 \\
\hline Concejo Laciana & 1718 & 146 & 23 & 15,8 \\
\hline Concejo de Laciana & 1761 & 482 & 104 & 21,6 \\
\hline Concejo de Laciana & 1775 & 160 & 28 & 17,5 \\
\hline Jurisdicción de Ancares & 1705 & 257 & 70 & 27,2 \\
\hline Concejo de Omaña & 1820 & 266 & 41 & 15,4 \\
\hline Montaña Central & 1786 & 235 & 38 & 16,2 \\
\hline Cea-Campos & $1653-56$ & 341 & 32 & 9,4 \\
\hline Cea- Campos & 1708 & 582 & 85 & 14,6 \\
\hline Cea-Campos & 1752 & 195 & 28 & 14,4 \\
\hline Grajal de Campos & 1735 & 86 & 10 & 11,6 \\
\hline Órbigo & 1662 & 301 & 35 & 11,6 \\
\hline Órbigo & 1704 & 582 & 133 & 22,8 \\
\hline Órbigo & 1708 & 150 & 20 & 13,3 \\
\hline Órbigo & 1715 & 168 & 18 & 10,7 \\
\hline \multicolumn{5}{|c|}{$\begin{array}{l}\text { Fuente: A. CH. V. (Archivo de la Real Chancillería de Valladolid) Protocolos y Padrones C. 148-6, } \\
\text { 149-9, 153-2, 168-1 y 2, 172-2, 187-4, 192-1. A. G.S. (Archivo General de Simancas). Expedientes } \\
\text { de Hacienda Leg. 112. A.H.P.L. (Archivo Histórico Provincial de León) C. 4248, 4249, } 9758,9962 \text { y } \\
\text { 10075. A.H.M.L. (Archivo Histórico Municipal de León) C. } 662 \text { y 629. }\end{array}$} \\
\hline
\end{tabular}

Esa inestabilidad que rigió los parámetros demográficos durante el Antiguo Régimen, tenía un reflejo inmediato en las estructuras familiares. De hecho, para un mismo territorio y una misma fecha, como fue el caso de la maragatería a mediados del siglo XVIII, se constata un comportamiento diferencial entre las familias campesinas y las arrieriles, con mayor poder económico. Si en las primeras el porcentaje de viudas al frente del hogar suponía el $18 \%$, en las otras esa cifra estaba casi diez puntos por debajo, como consecuencia de una mayor estabilidad matrimonial. Así pues, la causa de la desigual representación que tenían esas mujeres al frente del hogar, 
derivaba de una "mortalidad adulta social-diferencial", relacionada con la capacidad económica y la disponibilidad de alimentos ${ }^{20}$.

Las elevadas tasas de mortalidad ordinaria, aceleradas periódicamente por crisis económicas o sanitarias, golpeaban constantemente a la población y se dejaban sentir en los núcleos conyugales. Los efectos más inmediatos se hacían patentes en la composición del hogar, que podía ver alterada su tipología. Una serie de padrones elaborados a lo largo de la Edad Moderna nos permite observar la incidencia que dichas coyunturas tuvieron sobre las unidades domésticas. En la vega del Órbigo, en 1662 el porcentaje de mujeres que ostentaban la jefatura del hogar era de $11,6 \%$, en 1704 alcanzó el 23\%, cuatro años después, en 1708, descendió al 13,5\% y en 1715 cayó al 10,7\%. Coincide la primera fecha con una fase de expansión de la producción agraria y de crecimiento de la población. Tras ese periodo de calma, que parece que duró unos veinte años, comenzó una etapa de inestabilidad, salpicada por algunas décadas de relativa prosperidad, que llegó casi hasta los años veinte del siglo XVIII ${ }^{21}$. Parece, pues, que tales recesiones, generadas a raíz de la crisis económica finisecular y de la de comienzos de la centuria dieciochesca, así como la Guerra de Sucesión, fueron determinantes a la hora de colocar a las mujeres al frente de la familia. Esa situación vendría dada, sobre todo, por las dificultades de acceder a unas segundas nupcias, puesto que la mayor parte de ellas eran viudas; o, incluso, a unas primeras, y es que, aunque su representación era muy baja, también aparecen célibes al frente de los hogares. Las solteras tenían una ventaja de partida sobre las viudas: mayor facilidad para casarse, puesto que eran las más demandadas por solteros y viudos ${ }^{22}$. Por lo tanto, a las que habían perdido a sus maridos les quedaría un abanico más reducido de potenciales esposos ${ }^{23}$. Así mismo, tampoco debemos olvidar los efectos de la emigración en aquellos momentos coyunturalmente complicados, en los que las familias que tenían mano de obra excedente, por lo tanto también de consumidores de la despensa, se veían obligadas a expulsar efectivos, y éstos serían, fundamentalmente, varones jóvenes. En el Órbigo, una vez superadas las coyunturas recesivas y el conflicto bélico de comienzos del siglo XVIII, los valores que representan a las mujeres que eran responsables del hogar, de nuevo, se ajustaron, para situarse en los niveles de partida. Un comportamiento similar al de este territorio lo encontramos en

\footnotetext{
20 Rubio Pérez, L. M.: La burguesía maragata, León, Universidad de León, 1995, p. 139.

21 Rubio Pérez, L. M.: La Bañeza y su Tierra, 1650-1850. Un modelo de sociedad rural leonesa, León, Universidad de León, 1987, pp. 84-87.

22 La tendencia de los varones que se casaban por primera vez, a escoger solteras, fue de los motivos del descenso de las segundas nupcias entre las mujeres viudas. ToDD, B. J.: "The remarrying widow: a stereotype reconsidered", en Prior, M. (ed.): Women in English society 1500-1800, Londres, Methuen, 1985, pp. 54-92.

23 Tanto en La Bañeza como en el Bierzo o la montaña leonesa, el orden de enlaces matrimoniales, atendiendo al estado civil de los contrayentes era: entre solteros, viudo con soltera, viuda con soltero y entre viudos. En La Bañeza, de los enlaces en segundas nupcias, los porcentajes que correspondían a los celebrados entre viudos y solteras representaban entre el 60 y $63 \%$; los de soltera y viudo se movían entre 24 y $27 \%$ y los de viudos el 12\%; en el Bierzo, 51,9-58,4\%, 25,4-26,4\% y 15,2-22,4\%, respectivamente. Finalmente, en la montaña, fueron del $82,1 \%$, los que tuvieron lugar entre solteros, $12,7 \%$, viudo-soltera, 4,4\% solteroviuda y $0,8 \%$ entre viudos). Rubio Pérez, op. cit. (n. 21), pp. 120-121; BARTolomé Bartolomé, J. M.: Vino y viticultores en el Bierzo. Sociedad y estructuras económicas durante el siglo XVIII, León, Universidad de León, 1996, pp. 275-276. Pérez Álvarez, M. J.: La Montaña Noroccidental leonesa durante le Edad Moderna, León, Universidad de León, 1996.
} 
el Concejo de Luna, en la montaña, donde la inestabilidad económica de comienzos del siglo XIX colocó a un mayor número de mujeres al frente del hogar. Por su parte, en las Tierras de León se observa como la representación femenina, que se desprende de los padrones de 1561 y 1680 , justo antes de que las dificultades de finales de la centuria se dejaran sentir con fuerza, se mantuvo estable.

A través del catastro de Ensenada y de los padrones hemos podido comprobar como los porcentajes de mujeres que accedían a la jefatura del hogar ofrecían contrastes, más o menos acusados, entre zonas. Pero esos no sólo se dejaban sentir entre territorios alejados entre sí, regidos por diferentes estrategias hereditarias, matrimoniales o modelos culturales; también dentro de una misma comarca se hacían patentes. Pongamos el ejemplo del sureste de la provincia de León, donde existía una importante concentración de villas. En Grajal de Campos ${ }^{24}$, en 1708, había un 16,8\% de familias en las que la representación recaía en mujeres. Ese mismo año, tal porcentaje en Gordaliza del Pino, Gordoncillo o Valderas ${ }^{25}$ era del $12 \%, 8 \%$ y 14,6\%, respectivamente. Localidades no tan alejadas de aquellas, como Valencia de Don Juan o Toral de los Guzmanes $^{26}$, poseían un 5,7\% y 14,9\%. Unos años más tarde, en 1735, en Grajal, los hogares de jefatura femenina habían descendido a un 11,6\%. Todos esos resultados nos demuestra que, si bien fueron numerosos los factores - económicos, coyunturales, estrategias familiares, etc- que podían actuar, de forma aislada o vinculados entre sí, a la hora de dar un puesto de decisión a las mujeres, aún lo fueron más las coyunturas locales, muchas veces relacionadas con la eventualidad de las variables demográficas del momento.

\subsection{ESTADO CIVIL DE LAS MUJERES QUE EJERCÍAN COMO JEFAS DEL HOGAR}

Los principales soportes documentales para acercarnos un poco más al conocimiento de las mujeres que ejercían como jefas de hogar serán, de nuevo, los padrones y el catastro de Ensenada. En aquellos territorios donde fueron más generosos en la recopilación de los datos hemos podido conocer con quién vivía, la edad media que tenían en ese momento o el número de hijos u otros parientes que estaban bajo su responsabilidad. En principio, de las fuentes se desprende que el tamaño medio de los hogares gobernados por mujeres era menor que el de los varones ${ }^{27}$. En la montaña leonesa los grupos domésticos femeninos los formaban 2,7 personas, en el Bierzo Alto 2,2, en Sahagún 2,5 o en Villamor de la Vega 2,1. Por su parte, los gobernados por hom-

\footnotetext{
24 AHPL [Archivo Histórico Provincial de León], C. 628, n 59-56.

25 AHPL. C. $628, n^{\circ} 59-54,59-55$ y C. $643, n^{\circ} 59-178$.

26 AHPL. C. 644, no 59-187 y 643, no 59-158.

27 Respecto a las diferencias de tamaño entre los hogares masculinos y femeninos, vid. FERNÁNDEZ Cortizo, C.: "Mujer, vejez y grupo doméstico en la Galicia rural meridional a finales del Antiguo Régimen" [en línea]. Nuevo Mundo Mundos Nuevos, Coloquios, 24 de marzo 2008. http://www.nuevomundo.revues. org/29553 [Consulta: 14 agosto 2010]; GARcía GonzÁLEz, F.: "Mujer, hogar y economía familiar. Desigualdad y adaptación en la Sierra de Alcaraz a mediados del siglo XVIII”, Hispania, 95 (1997), pp. 115-145, p.121; Rey Castelao y Rial García, op. cit. (n. 16), pp. 96-97.
} 
bres poseían 4,3, 4,1, 3,6 y 3,3 individuos respectivamente ${ }^{28}$. El motivo de que estos últimos estuvieran más nutridos que los femeninos es fruto de varias circunstancias, tales como el menor número de núcleos masculinos que se hallaban rotos, a que eran muy pocos los de solitarios o a que estaban vinculadas, fundamentalmente, a varones las unidades domésticas en aquellas zonas donde la complejidad se había hecho un hueco en el modelo familiar.

El estado civil de las mujeres encargadas de sacar adelante a sus familias era mayoritariamente el de viudas. Sólo en la montaña la representación de las solteras tuvo cierta entidad. La responsabilidad que asumían unas y otras, lógicamente, era muy diferente. Pues, mientras eran muy pocas las solteras con cargas familiares -hijos, hermanas, sobrinos u otro tipo de parientes-, gran parte de las viudas tenían el compromiso de sacar adelante a sus hijos ${ }^{29}$.

La edad de las viudas varía mucho en función del momento coyuntural y del espacio sobre el que realicemos el cálculo. De forma global, podemos decir que estaba en torno a los cincuenta años, con un valor máximo de 53,3, para el Concejo de Laciana en 1718, y un mínimo de 48,5, en Cea-Campos en 1752. Los porcentajes de representación de esas mujeres, que habían perdido a sus esposos, dentro de lo que sería el universo familiar, se movió dentro de un amplio margen, dependiendo de las fechas y de las zonas. Así, por ejemplo, en el Órbigo nos encontramos con un $18,9 \%$ en 1704, mientras que en 1662 era del 11,6\%; en Cea-Campo el 14,4\% en 1752 y cinco puntos menos a mediados del siglo XVII; $17,6 \%{ }^{30}$ entre los campesinos maragatos a mediados de la centuria dieciochesca; o el 16,8\% en el Concejo de Laciana en 1761 y un $11,9 \%{ }^{31}$ catorce años después. En este caso concreto, y como ya hemos señalado, la pérdida de representación de esas mujeres estaría relacionada con el aumento que estaba teniendo lugar de familias complejas, dentro de las cuales quedarían absorbidas las viudas ${ }^{32}$ y las solteras.

28 Las dimensiones del hogar de jefatura masculina se asemejan a las de Reims, donde arrojaban una media de 3,6 miembros, no así los de femenina, que sólo tenían 1,9 miembros. Fauve Chamoux, A.: "Vedove di cittá e vedove di campagna nella Francia preindustriale: aggregato domestico, trasmissione e strategie familiari di sopravvivenza", Quaderni Storici, 2 (1998), pp. 301-332.

29 En lo que se refiere a las dificultades económicas por las que atravesarían estas unidades familiares, al igual que en el caso de las dirigidas por varones, estarían sometidas a una periodización. No obstante, en los hogares femeninos aquellas serían más intensas, debido a que eran más proclives a sufrir las consecuencias de la pobreza. Respecto a la relación entre el ciclo de la vida y los problemas económicos, Vid. GARCÍA GONZÁLEZ, F.: "Las estructuras familiares y su relación con los recursos humanos y económicos", en CHACÓN JIMÉNEZ, F. y Bestard Comas, J.: Familias. Historia de la sociedad española (del final de la Edad Media a nuestros días), Madrid, Cátedra, 2011, pp. 159-254 y 232.

30 Rubio Pérez, op. cit. (n. 21), p. 139.

31 El resultado que arroja el Concejo de Laciana para 1761 es casi idéntico al del vecino territorio gallego una década antes. DuBert GARcía, I.: Historia de la familia en Galicia durante la Época Moderna, 1550-1830, La Coruña, Ediciós do Castro, 1992, p. 62.

32 En la Vega del Esla, por su parte, el proceso expansivo que tuvo lugar entre mediados del siglo XVIII y 1841 dio lugar a un incremento de las familias extensas. Esa complejidad trajo como consecuencia un descenso de solitarias y también se dejó sentir en el retroceso de hogares femeninos al frente de los cuales estaba una viuda. PÉrez GarcíA, J. M.: Un modelo social leonés en crecimiento: la vega Baja del Esla entre 1700 Y 1850, León, Universidad de León y Universidad de Vigo, 1998, pp. 87. En Galicia, en las provincias donde había un mayor porcentaje de familias nucleares el número de mujeres que estaba al frente del hogar era superior al de aquellas otras donde existía una representación superior de estructuras complejas. Vid. 


\begin{tabular}{|l|c|c|c|c|c|c|c|c|c|}
\hline \multicolumn{1}{|c|}{ Cuadro no 3. Estado civil de las mujeres jefas de hogar } \\
\hline & & Solteras & $\%$ & Casadas & $\%$ & Viudas & $\%$ & Total & $\%$ \\
\hline C. de Sena de Luna & 1782 & 4 & 22,2 & & & 14 & 77,8 & 18 & 100 \\
\hline C. de Sena de Luna & 1806 & 2 & 9,1 & & & 20 & 90,9 & 22 & 100 \\
\hline C. de Babia de Abajo & 1761 & 35 & 36,5 & & & 61 & 63,5 & 96 & 100 \\
\hline Riaño & 1752 & 12 & 30,8 & 1 & 2,6 & 26 & 66,7 & 39 & 100 \\
\hline C. de Laciana & 1718 & 1 & 4,8 & 2 & 9,5 & 18 & 85,7 & 21 & 100 \\
\hline C. de Laciana & 1761 & 25 & 25,0 & & & 79 & 75,0 & 104 & 100 \\
\hline C. de Laciana & 1775 & 7 & 20,8 & & & 21 & 79,2 & 28 & 100 \\
\hline Cea-Campos & $1653-1656$ & & & & & 32 & 100,0 & 32 & 100 \\
\hline Cea-Campos & 1752 & & & & & 28 & 100,0 & 28 & 100 \\
\hline C.de Omaña & 1820 & 13 & 31,7 & & & 28 & 68,3 & 41 & 100 \\
\hline Grajal de Campos & 1735 & 2 & 20 & & & 8 & 80 & 10 & 100 \\
\hline Órbigo & 1662 & & & & & 35 & 100,0 & 35 & 100 \\
\hline Órbigo & 1704 & 23 & 17,3 & & & 110 & 82,7 & 133 & 100 \\
\hline Villademor de la Vega & 1752 & 3 & 6,5 & 1 & 2,2 & 42 & 91,3 & 46 & 100 \\
\hline
\end{tabular}

Por su parte, si calculamos el peso de las viudas dentro del colectivo femenino al frente del hogar, observamos como, salvo en la montaña, los porcentajes fueron idénticos, o estuvieron muy próximos (cuadro $\mathrm{n}^{\circ} 3$ ). El valor mínimo de aquellas lo encontramos en el Concejo de Babia en 1761, donde representaban el 63,5\%, y el máximo se registraba en Cea-Campos o en las tierras del Orbigo. En estas últimas zonas, para alguno de los años que conforman la muestra, todas las mujeres que estaban al frente del hogar habían accedido tras desaparecer el vínculo conyugal. De nuevo, y de forma genérica, vuelven a aparecer los dos grandes modelos provinciales: los territorios de montaña y las llanuras, ya sean vegas fluviales o espacios de secano. En estos últimos, la universalización del matrimonio se refleja en la práctica inexistencia de hogares con mujeres célibes al frente.

Teniendo en cuenta que fue en la montaña donde encontramos una representación más heterogénea del estado civil de las mujeres que ostentaban la jefatura del hogar, hemos querido profundizar sobre esta cuestión en ese territorio, para lo que hemos elaborado una muestra, a partir de casi mil doscientas familias ${ }^{33}$ (gráfico $\mathrm{n}^{\circ} 1$ ). En principio, es preciso señalar que, en la misma, las solteras representaban tercio de las féminas y las viudas prácticamente los dos restantes, pues la presencia de casadas resulta meramente testimonial (1,5\%). Casi el 50\% de las mujeres célibes tenían entre 18 y 35 años, por lo que no se trataría de hogares con una formación estable, ya que era en este grupo donde se incluirían las que, potencialmente, más posibilidades te-

SAAVEDRA Fernández, P.: "La vida cotidiana en la periferia de la civilización: los campesinos de Galicia en los siglos XVII-XIX”, Ayer, 19 (1995) pp. 101-133, p. 109 y 110.

33 Están representadas diferentes localidades de Babia, Omaña, Laciana y los Ancares. Pero no todas las familias que conforman la muestra nos has servido para realizar estos cálculos, pues, como ya hemos señalado, la edad de la mujer no siempre aparece recogida en los libros de familia del catastro del marqués de la Ensenada. Esa circunstancia, que afecta a buena parte del universo femenino leonés, no es exclusiva de esta provincia. Vid. Rial García, S.: "Las mujeres 'solas' en la sociedad semi-urbana gallega del siglo XVIII", Obradoiro de Historia Moderna, 8 (1999), pp. 169-197, p. 175. 
nían de acceder al matrimonio. A partir de los 35 la representación de solteras dejaba paso a las viudas, cuyo peso siguió una trayectoria inversa a las anteriores, y a partir de los 50 se concentraban en torno a la mitad de las mismas. Estas mujeres, debido a su edad, tendrían ya pocas posibilidades de entrar en los circuitos matrimoniales, por lo que la tipología de los hogares que regían, de no ser modificada tras el enlace de algún hijo, posiblemente quedaría inmovilizada hasta el fallecimiento de su titular. Por su parte, las que tenían al marido ausente aparecen solamente en tres tramos. El primero de ellos estaría relacionado con el reciente matrimonio y la necesidad de un trabajo que permitiera a la pareja reunir los ahorros necesarios para ir adquiriendo un patrimonio. En los otros, entre los 40 y 59 años, la ausencia posiblemente estuviera motivada por dificultades económicas puntuales, que pretendían paliar mediante un trabajo temporal, o quizá sus esposos ya hacía muchos años que estaban fuera ${ }^{34}$.

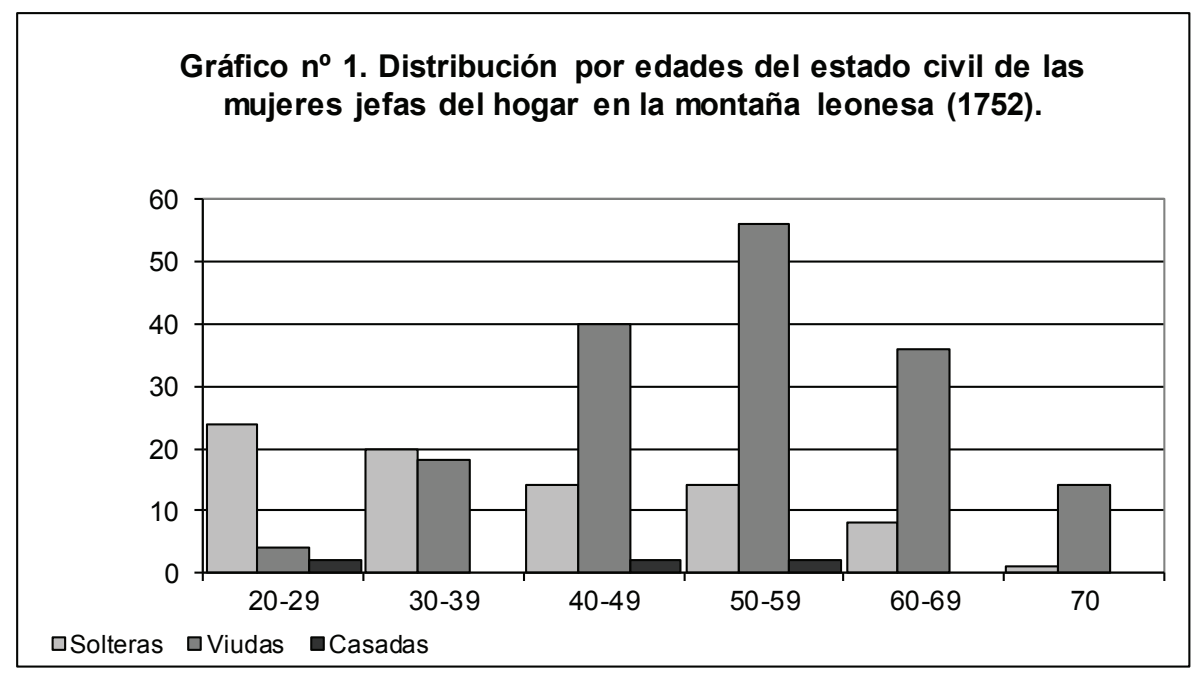

A su vez, en cuanto a la relación entre jefatura femenina y edad, en parte del ámbito rural leonés se repetía el mismo comportamiento que se ha constatado en Galicia: a más edad mayor porcentaje de mujeres responsable de la unidad familiar ${ }^{35}$. Por su parte, los resultados son diferentes si comparamos dos territorios de la provincia, cada uno de ellos con sus propios rasgos definitorios, en lo que respecta a estructuras demográficas, económicas o estrategias familiares, como eran la Montaña y las Vegas y Campos. En el primero, la jefatura femenina del hogar, a lo largo de todo el ciclo vital adulto, se mantuvo dentro de una franja porcentual mucho más estable que en

34 Los resultados que se desprenden de estos cálculos, de nuevo, son muy similares a los observados para la vecina Galicia, consecuencia del ciclo vital. Ambos territorios tienen en común el que la representación de las solteras al frente del hogar también comienza a descender a partir de los 50 años, a favor de las viudas. Muy similar será también el importante peso de éstas entre los 30 y 50 años, aunque en la montaña podríamos retrasarlo una década. No coinciden, en cambio, la distribución de las casadas por tramos de edad, pues allí estaban aumentando hasta los 40 años. Vid. Dubert García, op. cit. (n. 31), pp. 63-64.

35 Vid. Fernández Cortizo, op. cit. (n. 27). 
la otra (gráfico $\mathrm{n}^{\circ}$ 2). El mínimo se recoge a partir de los 70 años y el máximo entre los 50 y 59. Por lo que respecta a las Vegas y Campos, la representación de mujeres al frente de la unidad doméstica experimentaba un ascenso progresivo a medida que aquellas cumplían años (gráfico $\mathrm{n}^{\circ} 3$ ). De hecho, en estos territorios los porcentajes de esas mujeres por tramos de edad se movía en una horquilla mucho más elástica que en la montaña. Con valores mínimos, de poco más del 1\%, en aquellas unidades corresidenciales cuyas titulares no llegaban a la treintena, y un máximo del $42,9 \%$, por encima de los setenta ${ }^{36}$. Parece, pues, que en esas parcelas de la provincia marcadas por la nuclearidad familiar, la gran aliada de la mujer para ostentar la dirección del hogar era la vejez.
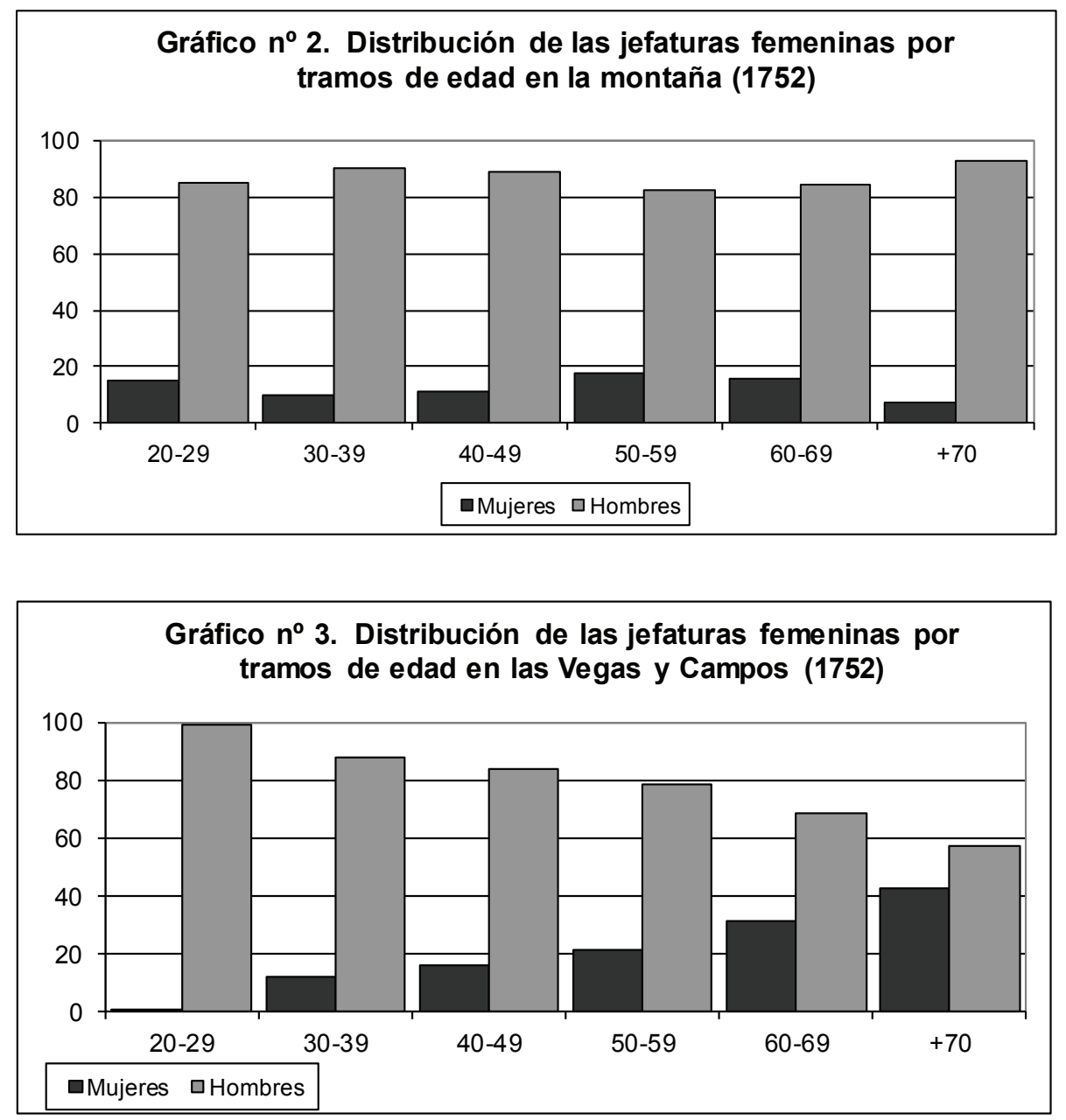

\footnotetext{
36 Los resultados que hemos obtenido en este territorio son exactamente los mismos que en ese momento arrojaban los datos de otra zona de corresidencia neolocal, como era Alcaraz de la Sierra. El 60\% de las mujeres jefas de hogar estaba por encima de los 45 años y algo menos del 20\% por debajo de los 35 . Vid. García González, op. cit. (n. 27), p. 121.
} 
Si comparamos jefatura femenina y masculina del hogar entre el norte y sur de la provincia, independientemente del estado civil de sus representantes, vemos como las curvas describían una trayectoria inversa, teniendo en ambos casos el punto de inflexión en los 50 años. A partir de esa edad, en las zonas donde la familia nuclear estaba más arraigada se producía un despegue de los hogares femeninos, cuya trayectoria tendía a converger con los de responsabilidad masculina; por el contrario, en la montaña las mujeres iban desapareciendo del puesto de dirección de la familia ${ }^{37}$ (gráfico $n^{\circ} 4$ ).

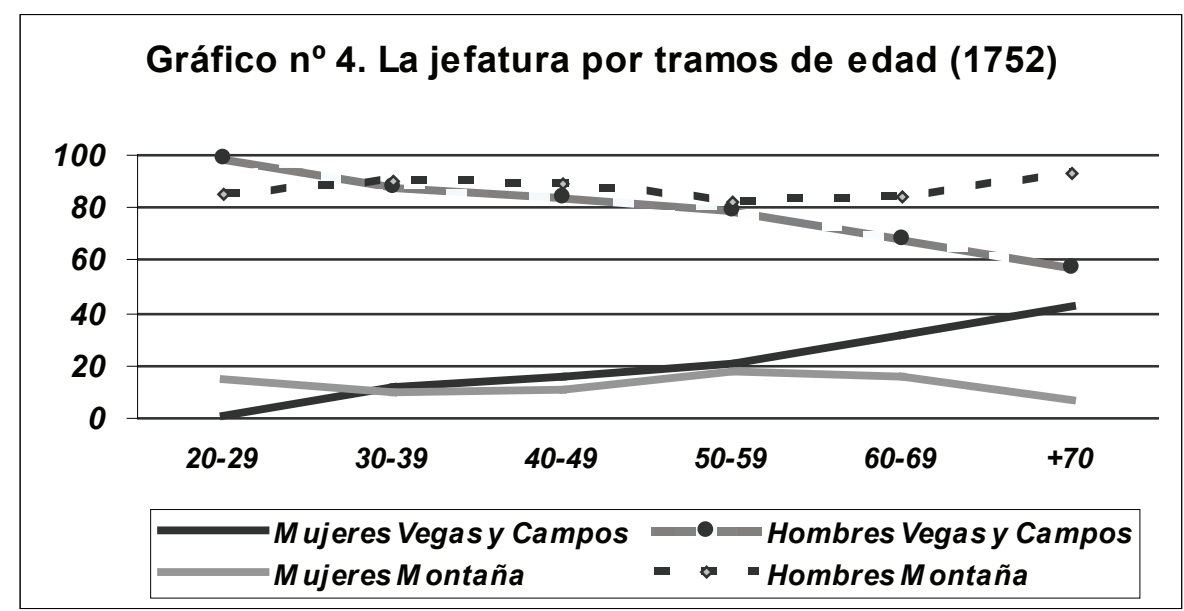

Volveremos a los datos que nos aportan las unidades domésticas de la montaña, puesto que es el modelo que más se apartaba del estandarizado de la provincia. En ese espacio geográfico, los sistemas familiares neolocales ${ }^{38}$, aunque también eran mayoritarios, no tenían la misma fuerza que en otras comarcas leonesas. El resultado era que el $71,9 \%$ de las mujeres que ostentaban la dirección del hogar superaban los 40 años y, dentro de éstas, era entre los 40 y 60 donde se agrupaba el mayor contingente. A partir de esa edad los porcentajes descendían bruscamente, pero no sólo por el efecto de la mortalidad. En el siglo XVIII la cohabitación de las mujeres sexagenarias respondía al siguiente esquema: el 34,6\% aún permanecían bajo la égida del

37 En la montaña gallega se repetía ese comportamiento: los porcentajes de viudas que vivían en soledad eran mayores que en otras zonas. Vid. Fernández Cortizo, op. cit. (n. 27), p. 8.

38 En los territorios que se regían por ese tipo de formaciones familiares los individuos tenían una mayor independencia de la autoridad paterna que en aquellos otros donde lo hacían por estructuras patrilocales. Burguiere, A.: "Pour une typologie des formes d'organisation domestique de l'Europe moderne (XVI-XIX) ", Annales E.S.C. (1986-3), pp. 639-655. Pero un predominio de residencia neolocal no significaba una ruptura de relaciones con la familia de origen. Vid. Hernández Bermejo, M. A.: "Estructuras familiares y sistemas de transmisión patrimonial en Extremadura. La ciudad de Coria en el siglo XVIII”, en GARCíA GonZÁLEZ, F. (ed.): Tierra y familia en la España Meridional, siglos XIII-XIX, Murcia, Universidad de Murcia, 1998, pp. 133-153, p. 152 y CASEY, J.: España en la Edad Moderna. Una Historia Social, Valencia, Universidad de Valencia, 2001, p. 318. 
esposo, algo más de un tercio de las mismas estaban al frente del hogar y un $26,9 \%^{39}$ residía con algún hijo casado. Prescindiendo de las que aún tenían vivo el núcleo conyugal e incluyendo en la muestra a todas las viudas con hijos solteros mayores de 25 años ${ }^{40}$, eran más las que no habían hecho dejación de sus funciones en la dirección del hogar que la habían traspasado a alguno de sus hijos. Ahora bien, si sólo incluimos en la muestra a aquellas que tenían a hijos casados con los que compartían residencia, entonces la situación cambia, abundaban más las unidades familiares en las que estaba al frente algún hijo ${ }^{41}$. Por otro lado, si comparamos edades de unas y otras observamos como las últimas tenían, por término medio, casi catorce años más que las anteriores. Todo ello nos indica que la decisión de apartarse de la jefatura estuvo mediatizada por dos cuestiones: por un lado la vejez y por otro y, quizá aún más determinante, el matrimonio de un hijo. Esas ancianas cumplirían un papel esencial en el núcleo doméstico, en tanto que actuaban como cuidadoras de los menores y participaban en otras actividades cuya destreza habían ido adquiriendo con la edad, tales como parteras o transmisoras de la herencia inmaterial, ya fuera ésta cultura oral o la memoria familiar y local ${ }^{42}$.

Tomando como referencia los datos que nos aportan los libros de familia del catastro de Ensenada para la montaña, hemos comprobado como gran parte de la complejidad que ofrecen las familias encabezadas por un hombre casado es el resultado de agregar mujeres a la unidad doméstica. Las hermanas célibes aparecen casi el triple de ocasiones que los hermanos que gozaban del mismo estado civil y se recogieron a más sobrinas y tías que parientes en el mismo grado del sexo masculino. Centrándonos en los ascendientes de la línea principal, la madre aparece en muchas más ocasiones que el padre y lo mismo ocurre con la suegra, aunque su presencia era más esporádica. A su vez, también era mucho más frecuente el desplazamiento de la nuera a la casa del esposo que a la inversa. Estas circunstancias se repiten lo mismo en hogares encabezados por hombres casados que por viudos. También los solteros eran proclives a recoger a sus madres y hermanas. Por su parte, entre la mujeres, tanto las solteras que compartían vivienda con alguno de sus familiares como las viudas, preferían la compañía femenina. Todos esos datos nos reiteran la corresidencia de mujeres mayores en el hogar de sus hijos casados. La pareja de acogida solían ser jóvenes que no haría muchos años que habían contraído matrimonio, pues la media de edad era de 32 años, y que, en detrimento de sus mayores, pasaron a encabezar el hogar.

El que esas viudas montañesas, en algún momento de su vida, renunciaran a la dirección del hogar en favor de uno de sus descendientes, dio lugar a una descom-

39 Se trata de una cifra más elevada que la obtenida en Galicia. Vid. Fernández Cortizo, op. cit. (n. 27), pp. 5-6.

40 La muestra la hemos basado en el concejo de Laciana y algunas localidades babianas. Hemos utilizados sólo los vecindarios, todos de la segunda mitad del siglo XVIII, y los núcleos familiares que nos aportaban datos completos de todos los miembros del hogar. En conjunto hemos reunido 160 unidades domésticas.

41 En el caso de la montaña leonesa el 76,8\% vivían en un hogar tutelado por un hijo casado, lo que supone un porcentaje más bajo que el de las tierras lucenses. Vid. Sobrado Correa, H.: Las tierras de Lugo en la edad moderna: Economía campesina, familia y herencia, 1550-1860, A Coruña, Fundación Pedro Barrié de la Maza, 2001, p. 72.

42 Rial García, S.: "Trabajo femenino y economía de subsistencia: el ejemplo de la Galicia moderna", Manuscrits, 27 (2009) pp. 77-99 y 85. 
pensación entre hombres y mujeres con el vínculo conyugal roto al frente del mismo. La proporción era de dos a uno. Por su parte, en los territorios rurales leoneses con una fuerte nuclearización, como Tierra de Campos o las Vegas, había más viudas que viudos al frente del hogar: de cada tres hogares de este tipo en torno a dos estaban bajo la dirección de una mujer, por ejemplo, en Cea-Campos la proporción se situaba entre 2,2 y 2,4 frente a 0,8 y 0,6 . Por lo tanto, y al margen de la mayor propensión de los varones a contraer segundas nupcias ${ }^{43}$ y de las dificultades de la viudas para acceder a un segundo matrimonio a partir de una determinada edad -que afectaría absolutamente a todas-, en los territorios donde la neolocalidad estaba más extendida no parece que esas mujeres tendieran a ampararse en los hogares de los hijos que se iban casando ${ }^{44}$, lo que no quiere decir que se rompieran los lazos materno-filiares de afectividad y solidaridad. Esas dos formas de organizar los años finales de su vida, que tuvieron las mujeres en la provincia leonesa, es la causa de las diferencias que existían en la media de edad entre los hombres y las mujeres viudos que ostentaban la jefatura del hogar en los dos ámbitos provinciales. En la montaña, la edad media del varón era muy superior a la de la mujer ( 57 frente a 45,3) y en las Vegas y Campos tendían a asemejarse ${ }^{45}$.

\section{MUJERES AUTÓNOMAS Y CORRESIDENCIA}

\subsection{LAS VIUDAS}

El 18,4\% de las viudas que vivían en el ámbito rural leonés lo hacían en solitari (cuadro $\mathrm{n}^{\circ} 4$ ). Unas, posiblemente, porque no les habían quedado hijos del matrimonio y otras porque esos ya se habían independizado. Pero teniendo en cuenta que su edad, con un importante peso de las que ya habían cumplido los 50, todo apunta a que el segundo caso era el más frecuente. Gran parte de esas mujeres, como ya hemos visto, siguieron con una vida autónoma, al menos en apariencia, pues las fuentes no siempre nos permiten conocer los lazos de dependencia económica, que podía surgir en los tramos de edad más elevados. Otras, quizás, acabarían teniendo necesidad de recurrir a su descendencia para que, normalmente a cambio de una mejora testamentaria, las cuidaran hasta el final de sus días. Pero también hubo casos, sobre todo en la parte septentrional de la provincia, donde, como ya hemos ido viendo, la emigración masculina estaba muy presente, en los que, en los que, en momentos difíciles, se encontraron totalmente desamparadas, por no saber nada de sus hijos. Así le ocurrió

43 Dubert, I.: Los comportamientos de la familia urbana en la Galicia del Antiguo Régimen. El ejemplo de Santiago de Compostela en el siglo XVIII, Santiago, Universidad de Santiago de Compostela, 1987, p. 42.

44 Igual que en Alcaraz, donde la tipología nuclear era la que presidía el modelo familiar, las viudas eran más proclives a mantener la dirección del hogar. Vid. García GonZÁlez, op. cit. (n. 16), p. 216.

45 En Asturias, dependiendo de la tipología familiar, también se observan diferencias de este tipo, aunque no en la misma línea que en la montaña leonesa. En la parte occidental del Principado, donde latía un modelo patriarcal y patrilocal, las mujeres que eran jefas del hogar tenían 4,6 años más que los hombres, en cambio en los otros territorios esa diferencia era de 6 años. Vid. López IgLesias, op. cit. (n. 16), pp. 92-104. 
a María de Omaña, vecina de San Miguel de Laciana, que en 1715 decía que su hijo estaba ausente desde hacia muchos años y no sabía "si estaba vivo o muerto"46.

\begin{tabular}{|l|c|c|c|c|c|c|c|}
\hline \multicolumn{7}{|c|}{ Cuadro n 4. La corresidencia en los hogares de jefatura femenina } \\
\hline & & \multicolumn{3}{|c|}{ Solteras \% } & \multicolumn{2}{c|}{ Viudas \% } & \\
\hline & Año & Viven solas & Con familia & Total & Viven solas & Con hijos & Total \\
\hline C. de Sena de Luna & 1782 & 100,0 & & 100 & 5,9 & 70,6 & 100 \\
\hline C. de Sena de Luna & 1806 & 100,0 & & 100 & 9,1 & 81,8 & 100 \\
\hline C. de Babia de Abajo & 1761 & 74,3 & 25,7 & 100 & 12,5 & 51,0 & 100 \\
\hline Riaño & 1752 & 75,0 & 25,0 & 100 & 13,2 & 55,3 & 100 \\
\hline C. de Laciana & 1718 & 100,0 & & 100 & 15,8 & 78,9 & 100 \\
\hline C. de Laciana & 1761 & 84,0 & 16,0 & 100 & 14,4 & 61,5 & 100 \\
\hline C. de Laciana & 1775 & 71,4 & 28,6 & 100 & 14,3 & 60,7 & 100 \\
\hline Cea-Campos & $1653-1656$ & & & 100 & 31,3 & 68,8 & 100 \\
\hline Cea-Campos & 1752 & & & 100 & 21,4 & 78,6 & 100 \\
\hline C.de Omaña & 1820 & 76,9 & 23,1 & 100 & 4,9 & 63,4 & 100 \\
\hline TOTAL & & 78,8 & 21,2 & 100 & 18,4 & 81,6 & 100 \\
\hline
\end{tabular}

En torno al $80 \%$ de las viudas vivían acompañadas de sus hijos ${ }^{47}$, con una media de entre 2 y 2,7 por hogar. Pero detrás de esa se escondían notables diferencias, y aunque la moda coloca bajo su responsabilidad entre 1 y 3 , había algunas que tuvieron que sacar adelante una considerable prole. Ese fue el caso de María Álvarez, vecina de la localidad babiana de Torrestío, que en 1752, con 50 años, tenía a su cargo 8 hijos. Esta mujer, que contaba con un patrimonio muy pequeño, estaba auxiliada económicamente por uno de los vástagos mayores, que trabajaba para la familia como arriero.

En los territorios del sur de la provincia, el porcentaje de mujeres viudas que vivían acompañadas de sus hijos coincidía, prácticamente, con el de los hogares nucleares. En la montaña era ligeramente más bajo, y, aunque en contadas ocasiones, también encontramos, junto a los descendientes, parientes ${ }^{48}$ en diferente grado, como posteriormente veremos. A su vez, y como reflejo de la tendencia que tenían las viudas de los territorios más nuclearizados a permanecer independientes aún en edades avanzadas, comprobamos como es en ellos donde aparecen los porcentajes más elevados de solitarias - entre el 21,4\% y $31,3 \%$, frente al 5,9\% y $15,8 \%$, que fue la franja en la que se movieron los datos que se desprenden de la montaña-.

Gran parte de esas viudas aún estaban en lo que podíamos considerar la primera fase de viudedad, puesto que los hijos que tenían a su cargo eran menores. Cuando estos alcanzaran la edad adulta entrarían en la segunda fase. En ese momento se podían dar dos circunstancias: que todos salieran del hogar buscando la indepen-

\footnotetext{
46 AHPL, C. 6544.

47 Porcentaje elevado si lo comparamos con el inglés, donde las viudas que vivían con hijos representaban el 60\%. Hufton, O.: "Women without Men: Widows and Spinsters in Britain and France in the Eighteenth Century", Journal of Family, 9 (1984), pp. 355-376 y 362.

48 También en Galicia la tipología familiar que más se repetía entre las viudas era la nuclear. Vid. REY Castelao y Rial García, op. cit. (n. 16), p. 95.
} 
dencia económica o que alguno de ellos permaneciera al lado de su madre. Es difícil saber cuál de esas direcciones tomarían esos hogares tutelados por las viudas. Tanto una circunstancia como la otra, indudablemente, estaría relacionada con la capacidad económica de la explotación familiar y la necesidad de brazos de trabajo. No obstante, los dos modelos hereditarios y matrimoniales que rigieron la provincia durante la Edad Moderna, y las pautas que nos ofrece la jefatura del hogar, podrán aportarnos indicios sobre esa cuestión.

Las zonas eminentemente agrícolas del sur de la provincia se caracterizaban, en el terreno demográfico, porque se casaban más jóvenes que en la parte septentrional y por la práctica ausencia de celibato. En ellas, la tipología familiar imperante era la nuclear y el modelo hereditario más extendido el reparto igualitario, corregido, en ocasiones, con pequeñas mandas y donaciones ${ }^{49}$. Por su parte, en aquellos territorios menos aptos para esa actividad económica, como era la montaña, había una mayor presencia de la patrilocalidad, el matrimonio se retrasaba y el celibato estaba más extendido. Por lo tanto, y según lo expuesto, en las zonas del sur esos hijos serían más precoces a la hora de abandonar el hogar; mientras en el norte, y enlazando con lo que hemos observado al analizar la jefatura del hogar de esas viudas, muchas de ellas acabarían cohabitando con uno de esos descendientes.

El caso de María de Lario, que vivía a finales del siglo XVI en una localidad de la montaña oriental leonesa, podría muy bien extrapolarse en el tiempo y en el espacio. Esa mujer, a la que se le había reconocido su pobreza en el padrón fiscal, había quedado viuda con cuatro hijos a su cargo, tres mujeres y un varón. Dos habían abandonado "esta jurisdicción" y "andan en servicio" mientras los otros aún permanecían a su lado. No sabemos a qué edad dejaron aquellos la casa familiar, pero, teniendo en cuenta la situación económica en la que vivían, consideramos que la búsqueda de unos medios de vida no debió demorarse mucho y, posiblemente, esa mujer no tardaría en ver como sus otros dos descendientes seguían ese mismo camino, precipitándola a una vida en solitario. Este patrón de comportamiento, detonante muchas veces de la soledad, sería el más repetido en los hogares a cuya cabeza se hallaba una mujer viuda y sin recursos, como también el de aquellos otros que se encontraban en la misma situación económica, aunque no se hubiera roto el núcleo conyugal.

Mientras esos hijos permanecieran en el hogar, indudablemente, contribuirían laboralmente a remediar económicamente a la familia. En este sentido son múltiples los casos que podríamos señalar. A mediados del siglo XVIII, María Manjarín, vecina de Lucillo tenía a dos de sus hijos solteros, Pedro y Josefa, dedicados a la actividad textil, por la que ingresaban cada uno tres reales al día. En las mismas fechas, vivía, en Villarino de Cabrera, Josefa Blanco con un hijo soltero, Juan Zamorano. Este muchacho, durante los meses de invierno, trabajaba como tejedor de lienzo grueso y estopa, por lo que obtenía una ganancia de 4 reales por día trabajado, y el resto del año se dedicaba a negociar con el vino que compraba en el Bierzo y Galicia, lo que le remuneraba unos 100 reales al año. Así mismo, otra actividad bastante generalizada

49 Pérez García, op. cit. (n. 32), pp. 85-111 y Martínez García, L.: El Páramo leonés durante la Edad Moderna. Bases estructurales, desarrollo económico y formas organizativas de un modelo social agrario, Tesis Doctoral inédita leída en la Universidad de León en el 2010. 
entre los menores era el pastoreo. A partir de los doce o catorce años, dependiendo de las localidades, la comunidad ya los autorizaba a ejercer ese oficio en las veceras, cobrando en algunas un pequeño salario, a veces en especie.

Cuando los hijos permanecían en el hogar, también en la evolución del mismo cabían dos posibilidades: que alguno de los que quedara asumiera la responsabilidad del mismo o que esa continuara recayendo en la madre. Como hemos visto anteriormente, era más frecuente el abandono de la jefatura en aquellos lugares con cierta complejidad familiar, como era la parte septentrional de la provincia. Así mismo, esa renuncia se daba, sobre todo, entre mujeres mayores, tras el matrimonio de alguno de sus hijos, aunque también las hubo que hicieron la cesión en célibes. Entre los hijos solteros que pasaron a detentar la jefatura del hogar tenemos a Antonio Álvarez, vecino de San Emiliano. En 1752, con 23 años, Antonio aparecía como responsable de una unidad doméstica en la que cohabitaba junto a su madre y un hermano. Este hombre, de oficio pastor, además, poseía una explotación que reunía unas 8 hectáreas de tierra, lo que suponía unas dimensiones considerables para la zona de la montaña. También Francisco Gómez, de Toreno del Sil, de 30 años, administraba, teóricamente, algo más de 11 hectáreas. Gran parte de las unidades familiares que se encuadraron en este grupo tenían algo en común: el tamaño de las explotaciones de las que eran responsables esos hijos célibes era superior al de la media de la zona, es decir, pertenecían al grupo de campesinos acomodados y ricos.

La aparente dejación en sus funciones, que hacían esas mujeres con mayores recursos económicos, podría estar relacionada con la forma de gobierno de las comunidades de aldea. En las reuniones concejiles, que eran el ámbito por excelencia de poder, las viudas sólo podían permanecer mientras exponían sus quejas u opiniones ${ }^{50}$, y en la mayoría de las localidades no tenían ni esa posibilidad. Sin embargo, las que contaban con hijos podían sortear aquella situación de subordinación a la que se veían sometidas por la comunidad, situando al frente del hogar a alguno de ellos en el momento que alcanzara la mayoría de edad. Otra cuestión que se nos escapa, y que también sería determinante a la hora de establecer la jefatura del hogar en circunstancias como las anteriores, son las últimas voluntades del padre de familia y la procedencia de esos bienes, es decir, si los detentaban por herencia paterna, eran de la madre o qué parte de ellos habían sido gananciales del matrimonio.

Un reducido número de esas viudas que vivían en compañía de sus hijos tenían, además, a otros parientes que cohabitaban en la unidad familiar. Estos casos, no muy elevados en el conjunto general, se concentraban mayoritariamente en los concejos de montaña. En esos territorios no es extraño encontrarse con hogares de este tipo a los que se añadían parientes por línea directa, como hermanos o nietos, o políticos,

\footnotetext{
50 “... si alguna vecina tuviere que proponer o repetir al concejo lo haga y hecho no se les consienta en él; y si laguna fuera impertinente y no quisiera marchar de dicho concejo u otra cualquiera junta que hagan los vecinos mandados por el regidor o alcalde pague pena de cuatro reales...". Ordenanzas de Marzán. AHPL, C. 6800. No era frecuente el permitir a las mujeres que asistieran a las reuniones concejiles e, incluso, en Riofrío de Órbigo, las acusaban de se incitadoras al escándalo - “... ninguna mujer sea osada a llegar al dicho concejo ni dar voces ni ruido en él... y escándalo que se da por ir dichas mujeres a Concejo"-, y les aconsejaban a las viudas que enviaran a alguno de sus hijos. RuBio Pérez, L. M.: El sistema político concejil en la provincia de León, León, Universidad de León, 1993, p. 443.
} 
por ejemplo, una nuera, un suegro o cuñados. Estos dos últimos suelen aparecer en los encabezados por las viudas más jóvenes, que se hacen cargo de los consanguíneos del que había sido su marido, el cual, posiblemente, había sido el elegido para recibir la mejora a cambio que permanecer en el hogar paterno. En esa circunstancia se hallaba María Rodríguez, vecina de Genestosa de Babia que, con 40 años, tenía a bajo su responsabilidad a dos hijos y al suegro. De todas formas, y dado que los padres retenían su herencia hasta los momentos finales de su vida, lo normal es que estas viudas aparezcan formando parte de un hogar que estaba bajo la titularidad del padre del que había sido su marido. Finalmente, hay otro pequeño grupo que estaba formado por toda una amplia gama de situaciones familiares. Por ejemplo, María González, de 62 años, en 1752 vivía en la localidad berciana de Toreno acompañada por tres nietos; otra mujer del mismo nombre, ésta de San Miguel de Laciana, tenía en su casa, en 1718, a una sobrina de 14 años, suponemos que para que la cuidase en su vejez, puesto que esta señora ya era septuagenaria.

\subsection{LAS SOLTERAS}

También el porcentaje de solteras titulares del hogar, como sucedía con las viudas, experimentó notables variaciones. En el Concejo montañés de Sena de Luna tan sólo significaban el $1,5 \%$ del vecindario en 1806 , justo la mitad que en 1782 . Por su parte, en el vecino de Laciana, sin apenas representación en 1718 (1\%), en 1761 alcanzaban al 5,2\% del total del vecindario. En el Órbigo, en 1662, no existía ninguna unidad familiar con una mujer célibe al frente, pero en 1704 eran el $4 \%$, casi todas menores ${ }^{51}$ que habían perdido a sus padres.

La mayor parte de esas mujeres $(78,8 \%)$ vivían solas. El resto compartían la vivienda con hermanos, que era lo más usual, otro tipo de parientes o, esporádicamente, con algún hijo. El colectivo de solteras se concentró, fundamentalmente, en la montaña, $y$, entre ellas, la formación familiar más extendida era la compuesta por dos hermanas, puesto que los varones solían emigrar. Así, Manuela Suárez Lanza, vecina de Caldas de Luna, declaraba en el padrón de 1815 que tenía dos hermanos, Manuel y Francisco, y que ambos estaban "ausentes del país". También fue en los concejos montañeses donde, como resultado de la emigración masculina, podemos encontrar con relativa frecuencia a mujeres que tuvieron hijos estando solteras. En aquella misma localidad, las hermanas Manuela y Joaquina Álvarez Juncar compartían vivienda con sus respectivos hijos "ignoran los empadronadores quienes fueron los padres de esas dos criaturas".

Esas hermanas y hermanos, que convivían en el hogar, formaban con sus legítimas una comunidad de bienes que les permitía salir adelante en mejores condiciones que por separado. Juana Rubio vivió con su hermano Juan, ambos solteros, hasta que ese falleció, dejándola como heredera de sus bienes. Poco después, una sobrina de

$51 \quad$ El porcentaje de mujeres solteras que ostentaban la jefatura del hogar se movió dentro de un amplio abanico en la Península. Entre los valores más bajos tenemos los de Extremadura en el siglo XVIII (1,2\%); a un nivel intermedio estaría Cuenca, que entre XVIII y mediados del XIX se situó en torno al 3\%; y de los más elevados serían los gallegos, 6,3\%. Blanco CARrasco, op. cit. (n. 14), p. 299; ReHer, op. cit. (n. 4); DuBerT García op. cit. (n. 31), p. 62. 
ambos, Antonia Carrera, reclamó la herencia de su tío. Juana tuvo que enfrentarse entonces a un importante problema. El testamento de su hermano se había perdido a causa "del tránsito de tropas y de las ocurrencias pasadas", por lo que en 1814 pedía que se presentaran ante el notario los que habían actuado como testigos de las últimas voluntades de su hermano, para que pudieran ser ratificadas ${ }^{52}$. De no acudir al llamamiento, la herencia se debía de repartir de forma igualitaria entre los herederos legales, quedando Juana en una difícil posición económica.

Muchas de esas mujeres que vivían solas, como también lo hicieron los hombres, ya fueran solteras o viudas sin descendencia, buscaron en un pariente, y a cambio de la herencia, la cobertura asistencial necesaria para el final de sus días. Esos acuerdos se plasmaban ante notario, bien en una escritura de donación ${ }^{53}$, de dote o en un testamento, que se hacía de forma anticipada, antes de enfrentarse a la enfermedad. Esa premura en registrar las voluntades se debería a la existencia de un interés, por parte del testante y del beneficiario. Éste buscaría asegurarse que la muerte repentina del donante no les apartara del disfrute de los bienes que les tenían apalabrados; y el otro, que la incertidumbre no repercutiera en el digno cuidado y enterramiento que esperaban recibir.

En cualquier caso, cuando se expresaban las intenciones en una escritura de dote, solitaria y solitario, al igual que quienes tenían descendencia, exigían compartir morada, efectuándose el traslado de la pareja joven, o del pariente sin más, a su casa, o a la inversa. Así mismo, los miembros de este colectivo también eran previsores en lo referente a desprenderse de la propiedad jurídica de los bienes ${ }^{54}$, la cual reservaban hasta el momento final de su vida. En aquellas otras situaciones en las que la decisión no se tomaba ante un inminente matrimonio, sino que simplemente se hacía una escritura de donación, esas solían recaer en mujeres ${ }^{55}$ que no habían sido mejoradas por sus padres. Esa circunstancia supuso regenerar las condiciones económicas de esas jóvenes, aunque sólo excepcionalmente las situaría en posiciones ventajosas, ya que el colectivo de solitarios/as no era el que más bienes acumulaba. Pero a diferencia de los casos anteriores, la mayor parte de las escrituras de este tipo que hemos encontrado correspondían a personas jóvenes y huérfanas ${ }^{56}$.

\footnotetext{
52 AHPL, C. 6728.

53 María García, de Montrondo, impedida de pies y manos, en 1750, donaba sus legítimas a sus hermanos, a cambio de su protección. AHPL, C. 6784.

54 María Álvarez, de Villanueva de Omaña, “...soltera mayor e incapacitada”, donó todos sus bienes a Pedro Iglesias, a cambio de que la cuidara y alimentara. Se reserva la capacidad de poder de vender lo que necesitara a lo largo de su vida. AHPL, C. 6784.

55 Pérez Álvarez, M. a J.: "Familia y estrategias familiares en el marco de unas estructuras socioeconómicas tradicionales: El modelo de la montaña noroccidental leonesa en la Edad Moderna", Revista de Demografía Histórica, 22 (2004), pp. 121-148.

56 Francisca Álvarez, soltera, dejaba como heredero a su hermano y legaba a su hermana 100 ducados en dote, si llegaba a casarse, o "200 ducados si no llegara a tomar estado". AHPL, C. 6730
} 


\section{CONCLUSIÓN}

Del análisis territorial que hemos realizado, sobre los hogares que tenían al frente a una mujer, nos encontramos en la provincia León, para mediados del siglo XVIII, con dos zonas bien delimitadas: el norte montañoso y las zonas agrícolas del sur y sureste. En el primero, el acceso de las mujeres a la responsabilidad doméstica se producía con más frecuencia que en el segundo, predominando las viudas sobre las solteras. Esta preponderancia se convertía en un dominio casi absoluto en las tierras del sur. Por otro lado, en la parte septentrional los padrones nos ponen de manifiesto que, con cierta frecuencia, existía una delegación de funciones de las mujeres viudas en sus hijos, que comenzaría con la cesión de la titularidad del hogar. No obstante, esas evidencias, cuando podemos cotejarlas con un algún tipo de fuente que nos ofrezca información sobre el patrimonio, parece que tenían lugar, sobre todo, entre las familias que se encuadraban dentro de lo que podríamos considerar medianas o ricas explotaciones. El origen de ese tipo de comportamientos podría derivar, de la necesidad de tener presencia en las reuniones concejiles, lo que se lograría a través de una figura masculina; así mismo, y teniendo en cuenta que entre esos grupos era frecuente que se recurriera a algún tipo de mejora testamentaria, podría ser que el hijo, que le daba el relevo a la madre, fuese el elegido para beneficiarse de la misma, es decir, el encargado de prolongar la casa, con todas las connotaciones que conlleva, más allá de la generación que estaba extinguiéndose. Comportamientos de ese tipo no se detectan en el segundo de los ámbitos señalados, donde también había reuniones concejiles, pero, en cambio, las herencias eran igualitarias, lo que suponía que cada uno de los descendientes tomaba el relevo generacional fuera del hogar paterno. De todas formas, y al margen de la implicación que pudiera tener el sistema hereditario en ese tipo de conductas, no hemos de olvidar que la renuncia a la dirección del hogar no significaba una dejación en la toma de decisiones.

Esas diferentes maneras de comportamiento observadas en ambas zonas, era el resultado de vincularse toda una serie de variables, que eran las que, en último término, determinaban las estructuras de cada territorio. En la montaña, la baja productividad del terrazgo obligaba adaptar el modelo matrimonial para evitar un crecimiento demográfico que no se tenía capacidad de absorber. Entre las estrategias que se arbitraron con esa finalidad estaban el celibato y la intensidad matrimonial. Ambas afectaron fundamentalmente a las mujeres, pues, además, estuvo muy presente la emigración masculina. De todas esas circunstancias derivaron los elevados porcentajes de mujeres que aparecen al frente del hogar en los territorios más pobres, que eran los de mayor altitud geográfica en la provincia. Pero, además, hemos de tener en cuenta que esas cifras están subestimadas, pues debido a las prácticas sucesorias que se ponían en marcha en esos territorios, que privilegiaban al sexo masculino, muchas de las viudas y solteras adultas quedaban absorbidas en esos hogares. Por su parte, en las zonas donde había tierra en abundancia o aquella era muy productiva, los comportamientos demográficos y familiares eran otros: las mujeres podían acceder con mayor facilidad al matrimonio, lo hacían a una edad más temprana e incluso podían permitirse unas segundas nupcias, y el modelo de corresidencia, casi universal, era el neolocal. 
Pero no sólo las estructuras fueron determinantes a la hora de otorgar la dirección del grupo doméstico a las mujeres; también, a corto plazo, las coyunturas provocaban que su presencia estuviera sometida a constantes oscilaciones. De hecho, en momentos de crisis la representación de las mujeres era mucho más importante que durante los periodos de estabilidad.

Una vez realizado el análisis territorial, sus resultados nos abren un amplio abanico de posibilidades para acometer una segunda fase de estudio. Si en esta primera hemos constatado como, efectivamente, existieron al menos dos modelos estructurales, en lo que se refiere a la jefatura femenina del hogar, sería conveniente que la próxima tuviera como objeto profundizar en las diferencias internas que pudieran existir dentro de cada uno de ellos. En este sentido, el objeto de estudio sería medir cómo las diferencias económicas, que como se ha detectado parece que cumplieron un papel importante, influyeron en los modelos organizativos o el tipo de formaciones familiares que rigieron esas mujeres, en función de la situación socioeconómica de la que disfrutaban o de la etapa en la que se encontraba su ciclo vital. 